University of South Florida

DIGITAL COMMONS

Digital Commons @ University of

@ UNIVERSITY OF SOUTH FLORIDA

South Florida

$1-1991$

\title{
A Description of the Annual Cycle in Sea Surface Temperature and Upper Ocean Heat in the Equatorial Atlantic
}

Thomas J. Weingartner

University of South Florida

Robert $\mathrm{H}$. Weisberg

University of South Florida, weisberg@marine.usf.edu

Follow this and additional works at: https://digitalcommons.usf.edu/msc_facpub

Part of the Marine Biology Commons

\section{Scholar Commons Citation}

Weingartner, Thomas J. and Weisberg, Robert H., "A Description of the Annual Cycle in Sea Surface Temperature and Upper Ocean Heat in the Equatorial Atlantic" (1991). Marine Science Faculty Publications. 144.

https://digitalcommons.usf.edu/msc_facpub/144

This Article is brought to you for free and open access by the College of Marine Science at Digital Commons @ University of South Florida. It has been accepted for inclusion in Marine Science Faculty Publications by an authorized administrator of Digital Commons @ University of South Florida. For more information, please contact digitalcommons@usf.edu. 


\title{
A Description of the Annual Cycle in Sea Surface Temperature and Upper Ocean Heat in the Equatorial Atlantic
}

\author{
THOMAS J. WEINGARTNER* AND ROBERT H. WEISBERG \\ Department of Marine Science, University of South Florida, St. Petersburg, Florida
}

(Manuscript received 8 February 1990, in final form 11 July 1990)

\begin{abstract}
Temperature and velocity time series, obtained by surface moorings during the Seasonal Response of the Equatorial Atlantic Experiment, are used to investigate the role of ocean dynamics upon the annual cycle of equatorial sea surface temperature (SST) and upper ocean heat. The annual cycle in SST is explained by different mechanisms, each operant at different phases of the cycle. The boreal springtime decrease in SST results from upwelling in response to the seasonal intensification of easterly wind stress. This upwelling causes the seasonal formation of the cold tongue along the equator in the central and eastern portions of the basin. An early summer increase in SST is attributed to the meridional convergence of Reynolds' heat flux associated with surface current instability-generated waves. After the instability waves abate, SST and mixed layer depth remain relatively steady from late summer through fall when the advective terms are small and cancelling, suggesting that surface heating is then balanced by a diffusive flux at the base of the mixed layer. SST increases in wintertime following the seasonal relaxation in easterly wind stress, thus, completing its annual cycle. This increase is attributed to the concentration of the surface flux over a mixed layer that is shoaling due to both the basin-wide adjustment of the thermocline and the local reduction in turbulent energy production. Thus, SST variations are found to be most closely controlled by ocean dynamics during those times when the thermocline is adjusting basin-wide to the seasonal changes in wind stress; either directly by large advective fluxes (boreal spring-summer) or indirectly by mediating mixed layer depth (boreal winter). Analyses at $75 \mathrm{~m}$ depth show zonal and vertical advection to be important, and within a control volume over the upper $150 \mathrm{~m}$ all of the advective terms are important.
\end{abstract}

\section{Introduction}

The oceanic and atmospheric circulation systems provide the poleward transport of heat necessary to maintain the Earth's radiation balance with the coupling of these two fluid media controlled largely by sea surface temperature (SST). Bjerknes (1966, 1969) connected variations in equatorial SST with variations in the extratropical atmospheric circulation, thus, catalyzing oceanographic investigations into the processes that control equatorial SST.

Equatorial oceans, characterized by a vigorous threedimensional circulation and large temperature gradients, respond rapidly to changes in wind-stress forcing. Advective effects are therefore important in the seasonal evolution of SST. Recent numerical model (e.g., Schopf and Harrison 1983; Sarmiento 1986; Philander and Pacanowski 1986; and Seager et al. 1988)

\footnotetext{
* Present Address: Institute of Marine Science, University of Alaska, Fairbanks, Alaska.

Corresponding author address: Dr. Robert H. Weisberg, Department of Marine Science, University of South Florida, St. Petersburg, FL 33701.
}

and climatological data (e.g., Wyrtki 1981; Enfield 1986 ) studies support this assertion. However, attempts at corroborating these results have met with only partial success due to limited and largely nonsynoptic sampling (e.g., Stevenson and Niiler 1983; Molinari et al. 1985).

During the Seasonal Response of the Equatorial Atlantic (SEQUAL) Experiment, time series of temperature and horizontal velocity were collected from an array of four current meter moorings centered on the equator at $28^{\circ} \mathrm{W}$. These data are used to examine the role of ocean dynamics in the seasonal evolution of SST and upper ocean heat. Section 2 describes the data and the computational procedures. A description of the seasonal variations of the wind and the upper ocean is presented in section 3. The evolutions of the temperature balances on the equator at $28^{\circ} \mathrm{W}$ at depths of 10 and $75 \mathrm{~m}$ and vertically integrated over the upper $150 \mathrm{~m}$ for the period March 1983-March 1984 are presented in section 4 . The discussions in section 5 then focus on 1) the relative importance of atmospheric heating and vertical diffusion in the SST balance compared with the advective heat fluxes and 2) the representativeness of the SST evolution observed at this location and year to other equatorial longitudes and years. Section 6 provides a summary. 


\section{Data and methods}

The local rate of change of temperature, formed as a running mean over a specified time interval, varies in accordance with advective and diffusive processes as

$$
\begin{aligned}
T_{t}=-(u T)_{x}- & (v T)_{y}-(w T)_{z} \\
& -\left\langle u^{\prime} T^{\prime}\right\rangle_{x}-\left\langle v^{\prime} T^{\prime}\right\rangle_{y}-\left\langle w^{\prime} T^{\prime}\right\rangle_{z}
\end{aligned}
$$

where $T$ is temperature, $(u, v, w)$ are the zonal, meridional, and vertical components of velocity and the subscripts denote partial differentiation in time $(t)$ and in the zonal, meridional, and vertical directions $(x, y$, $z$ ). The bracketed terms, as covariances over a specified running mean interval, represent diffusive temperature changes by turbulent Reynolds' flux convergences. These Reynolds' flux convergences result from the rectification of the large scale velocity and temperature fluctuations and should not be confused with additional diffusive heat fluxes resulting from unresolved smaller scale turbulence. Application of the continuity equation results in

$$
\begin{aligned}
T_{t}^{*}=-u T_{x}-v T_{y}-w T_{z} & -\left\langle u^{\prime} T^{\prime}\right\rangle_{x} \\
& -\left\langle v^{\prime} T^{\prime}\right\rangle_{y}-\left\langle w^{\prime} T^{\prime}\right\rangle_{z}
\end{aligned}
$$

and this equation is used to diagnose the temperature balance at 10 and $75 \mathrm{~m}$ depths. Current meter data, when used to calculate the terms on the right-hand side of Eq. (2), result in the estimate $T_{t}^{*}$, which will be compared with the observed $T_{t}$, evaluated directly from the temperature data.

Using instantaneous values Eq. (1), integrated from the surface where $w=0$ to some depth $-z_{1}$, gives the rate of change of upper ocean heat due to advective processes:

$$
\begin{aligned}
\rho C_{p} \int T_{t}^{*} d z=-\rho C_{p} \int\left[(u T)_{x}\right. & \left.+(v T)_{y}\right] d z \\
& +\left.\rho C_{p} w T\right|_{z=-z_{1}}
\end{aligned}
$$

where $\rho$ and $C_{p}$ are the seawater density and specific heat at constant pressure, respectively. Equation (3) is used to diagnose the heat balance over the upper 150 $\mathrm{m}$ of the water column.

The current meter moorings employed in this study were located on the equator at $28^{\circ}$ and $24^{\circ} \mathrm{W}$ and along $28^{\circ} \mathrm{W}$ at $0.75^{\circ} \mathrm{N}$ and $0.75^{\circ} \mathrm{S}$. Table 1 shows the instrument locations, types (EG \& G Sea Links Systems vector averaging and vector measuring current meters, VACMs, and VMCMs, respectively) and sampling durations. Concurrent data are available at 75 and 150 $\mathrm{m}$ depths for the period from 4 March through 2 November 1983 and at $10 \mathrm{~m}$ depth through 20 March 1984 with one exception - velocity at $10 \mathrm{~m}$ depth at $0^{\circ} \mathrm{N}, 24^{\circ} \mathrm{W}$ from 17 May through 20 September 1983 . The $u$-component for this record gap is interpolated by linear mean square estimation using $u_{x}$ at $50 \mathrm{~m}$ depth, as calculated in Weingartner and Weisberg (1991; hereafter referred to as WW). Horizontal velocity and temperature data at depths of 10,75 , and $150 \mathrm{~m}$ along with $w$-component time series estimated by WW are used to calculate the terms in Eqs. (2) and (3). Additional temperature data from $0^{\circ} \mathrm{N}, 28^{\circ} \mathrm{W}$ at depths of 50,100 , and $200 \mathrm{~m}$ are used to describe the variations in upper-ocean heat at this location. Discussions of the finite difference procedures and estimation errors are given in the Appendix where the

\begin{tabular}{|c|c|c|c|c|}
\hline \multirow[b]{2}{*}{ Position } & \multirow[b]{2}{*}{$\begin{array}{c}\text { Depth } \\
\text { (m) }\end{array}$} & \multirow{2}{*}{$\begin{array}{c}\text { Instrument } \\
\text { type }\end{array}$} & \multicolumn{2}{|c|}{ Duration } \\
\hline & & & Start & Stop \\
\hline $0^{\circ} 00^{\prime} \mathrm{N}$ & 10 & VACM & 190013 Feb 1983 & 190020 Mar 1984 \\
\hline \multirow{5}{*}{$28^{\circ} 09^{\prime} \mathrm{W}$} & 50 & VACM & 190013 Feb 1983 & 190020 Mar 1984 \\
\hline & 75 & VACM & 190013 Feb 1983 & 190020 Mar 1984 \\
\hline & 100 & VACM & 190013 Feb 1983 & 190020 Mar 1984 \\
\hline & 150 & VACM & 190013 Feb 1983 & 20003 Nov 1983 \\
\hline & 200 & VACM & 190013 Feb 1983 & 190020 Mar 1984 \\
\hline $0^{\circ} 03^{\prime} \mathrm{N}$ & 10 & VMCM & $1600 \quad 3$ Mar 1983 & 230017 May 1983 \\
\hline \multirow[t]{3}{*}{$23^{\circ} 59^{\prime} \mathbf{W}$} & 10 & VMCM & 000021 Sep 1983 & 100028 Mar 1984 \\
\hline & 75 & VACM & $1600 \quad 3 \operatorname{Mar} 1983$ & $100028 \mathrm{Mar} 1984$ \\
\hline & 150 & VACM & 16003 Mar 1983 & $100028 \mathrm{Mar} 1984$ \\
\hline $0^{\circ} 44^{\prime} \mathrm{N}$ & 10 & VACM & 230010 Feb 1983 & $070022 \mathrm{Mar} 1984$ \\
\hline \multirow[t]{2}{*}{$28^{\circ} 11^{\prime} \mathrm{W}$} & 75 & VACM & 230010 Feb 1983 & $070022 \mathrm{Mar} 1984$ \\
\hline & 150 & VACM & 230010 Feb 1983 & 070022 Mar 1984 \\
\hline \multirow{3}{*}{$\begin{array}{l}0^{\circ} 45^{\prime} \mathrm{S} \\
28^{\circ} 10 \mathrm{~W}\end{array}$} & 10 & VACM & 220014 Feb 1983 & $160021 \mathrm{Mar} 1984$ \\
\hline & 75 & VACM & 220014 Feb 1983 & 20003 Nov 1983 \\
\hline & 150 & VACM & 220014 Feb 1983 & $160021 \mathrm{Mar} 1984$ \\
\hline
\end{tabular}
terms in Eq. (2) are evaluated to be consistent with mass conservation as in the WW diagnosis of the continuity equation.

TABLE 1. The moored current meter locations, types, and sampling durations used in diagnosing the temperature and upper-ocean heat balances. 


\section{Seasonal variability in the winds and the upper ocean}

Low frequency variability within the equatorial waveguide is effected primarily by the zonal integral of easterly wind stress (e.g., Cane and Sarachik 1977; Moore and Philander 1977). Using SEQUAL data, Weisberg and Tang (1987), Weisberg et al. (1987), and WW have discussed the seasonal evolution of the upper-ocean temperature and velocity fields along the equator in response to the basinwide seasonal wind stress transitions. Figure 1 shows time series of the surface eastward wind stress component from Saint Peter and Paul Rocks (SPPR), located at $1^{\circ} \mathrm{N}, 29^{\circ} \mathrm{W}$, for the periods mid-February-mid-November 1983 and January-March 1984, as reported by Garzoli and Katz (1984). Supplemental wind data from the buoy at $0^{\circ} \mathrm{N}$, $24^{\circ} \mathrm{W}$ are also available from September 1983 through January 1984 (R. Payne, personal communication) to fill the SPPR record gap. These data have been lowpass filtered to exclude oscillations at periods shorter than four days using a truncated Fourier transform. The combined record begins by showing weak easterly wind stress, briefly relaxing to zero from late March through early April. Then, in early April, the easterlies rapidly intensify to the stronger levels observed from mid-May through mid-November. Upon resumption of the SPPR record in January 1984 the easterlies are again weak and remain so through March 1984. The $0^{\circ} \mathrm{N}, 24^{\circ} \mathrm{W}$ record adds to this description by showing that the seasonal relaxation in the easterlies also occurs rapidly, beginning in mid-December 1983 .

To preface the discussions of the temperature and heat balances, Figs. 2 and 3 show time series of the temperatures, the temperature gradients and the velocity components used to evaluate Eq. (2) and (3), calculated as four-day running means. The seasonal variations in temperature at $10 \mathrm{~m}$ depth (a proxy for SST) and in the thermocline are in response to the seasonal changes in easterly wind stress. The March 1983 easterly wind stress relaxation event results in an increase in SST and temperature at $75 \mathrm{~m}$ depth by $1^{\circ}-$ $2^{\circ} \mathrm{C}$ within about two weeks. As the easterlies intensify in early April, SST and temperature at $75 \mathrm{~m}$ depth decrease by $3^{\circ}-4^{\circ} \mathrm{C}$ over roughly a month. Then the evolutions of SST and temperature at $75 \mathrm{~m}$ depth diverge, despite the persistence of strong easterlies throughout boreal summer and fall. SST stops decreasing in mid-May with the appearance of waves with 25day period that are generated by surface current instability (Philander et al. 1987; Weisberg and Weingartner 1988). During this time the thermocline is deepening due to its basinwide adjustment to increased easterlies (Weisberg and Tang 1987), and this is reflected in the $6^{\circ} \mathrm{C}$ rise in the temperature observed at $75 \mathrm{~m}$ depth from mid-May through July. After July SST and temperature at $75 \mathrm{~m}$ depth both remain at relatively constant levels through early December. As the easterlies begin to relax in early December, SST begins to increase steadily, thus completing its annual cycle. However, the evolution of temperature at $75 \mathrm{~m}$ depth again diverges from that of SST. Weisberg and Tang (1987) show that the thermocline's response to this relaxation involves a sequence of deepening followed by shoaling, and this behavior is reflected by the increase in temperature at $75 \mathrm{~m}$ depth from mid-December 1983 through mid-January 1984 followed by the decrease observed in February. The seasonal evolution of the vertically integrated heat parallels the displacement of the thermocline as reflected in the temperature at 75 m depth.

The $u-, w-$, and $v$ - (temperature gradient) component time series at 10 and $75 \mathrm{~m}$ depths are shown in Fig. 3a (Fig. 3b). Following the methodology in the Appendix the $u-(v-)$ component is the average of the $u$ - $(v$ - $)$ components at $0^{\circ}, 28^{\circ} \mathrm{W}$ and $0^{\circ}, 24^{\circ} \mathrm{W}$ $\left(0.75^{\circ} \mathrm{N}, 28^{\circ} \mathrm{W}\right.$ and $\left.0.75^{\circ} \mathrm{S}, 28^{\circ} \mathrm{W}\right)$. At $10 \mathrm{~m}$ depth, steady eastward flow is observed from March through May, followed by more variable but generally westward flow over the remainder of the record. This differs from the climatological description of Richardson and McKee (1984) which indicates a strong westward flowing South Equatorial Current (SEC) on the equator throughout the year. At $75 \mathrm{~m}$ depth the eastward flow varies seasonally with the vertical position of the thermocline and hence the vertical position of the Equatorial Undercurrent (EUC). Maximum speeds are observed from March through mid-May when the EUC core is located at about $75 \mathrm{~m}$ depth and minimum speeds are observed after the core of the EUC deepens with the thermocline.

The zonal temperature gradient $\left(T_{x}\right)$ is generally directed westward. At the surface it is largest during the summer months when the easterlies are strongest. At $75 \mathrm{~m}$ depth it is largest in springtime as the thermocline undergoes adjustment to the rapidly intensifying easterlies. This period of adjustment also includes higher frequency variability due to the instability waves.

The $w$-component at 10 and $75 \mathrm{~m}$ depths were estimated and discussed by WW. Following the short but basinwide easterly wind stress relaxation event in March, a 10-day period of intense downwelling is observed at 10 and $75 \mathrm{~m}$ depth. Then, upon the seasonal intensification of easterly wind stress, upwelling is observed for about 4-6 weeks. Oscillations in $w$ follow during the instability wave season afterwhich downwelling is observed on average from mid-July through September. This upwelling/downwelling sequence is a result of the basinwide thermocline adjustment. After the thermocline adjusts, $w$ at $10 \mathrm{~m}$ varies coherently with the easterly wind stress component.

The seasonal variations in the vertical temperature gradients at 10 and $75 \mathrm{~m}$ depths reflect the seasonal variations in the thermocline depth. These gradients are largest (smallest) in the spring and winter (summer and fall) when the thermocline is shallowest (deepest). During periods of upwelling $T_{z}$ at $10 \mathrm{~m}$ depth is esti- 


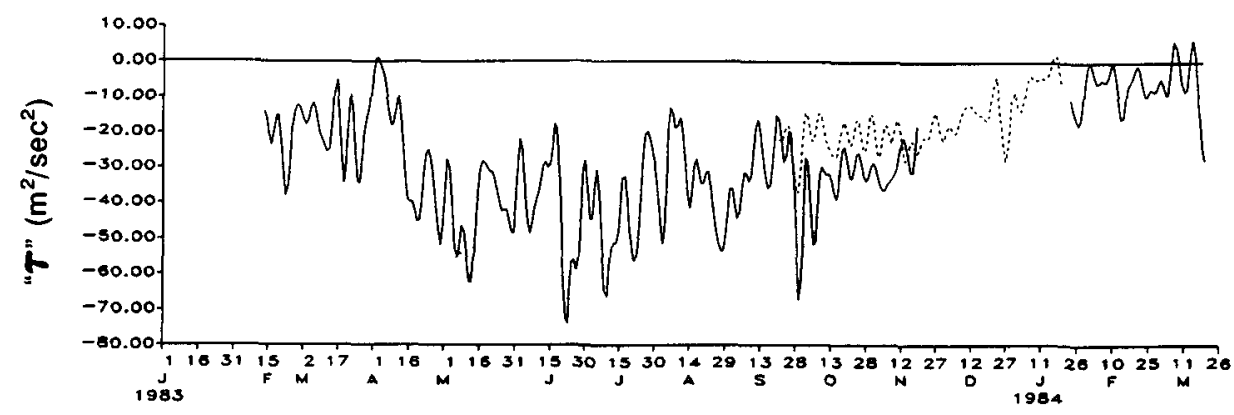

FIG. 1. Zonal (" $\tau^{x "}$ ) surface wind stress component proportional at SPPR (solid line) and at $0^{\circ} \mathrm{N}$, $24^{\circ} \mathrm{W}$ (dashed line), low-pass filtered to exclude fluctuations at time scales shorter than 4 days.

mated from temperature data at 10 and $50 \mathrm{~m}$ depths as shown in Fig. 3b. During periods of downwelling $T_{z}$ at $10 \mathrm{~m}$ depth is estimated from temperature data at the surface and at $10 \mathrm{~m}$ depth using the instruments moored at $0^{\circ}, 15^{\circ} \mathrm{W}$. From these latter data $T_{z}$ equals $0.4^{\circ} \mathrm{C} / 10 \mathrm{~m}$ over the period 25 March-9 April 1983 and $0.1{ }^{\circ} \mathrm{C} / 10 \mathrm{~m}$ over the remainder of the record. The important point is that even during the downwelling periods there exists significant $T_{z}$ over the upper $10 \mathrm{~m}$, affecting the temperature balance there.

The $v$-component oscillations are small with the exception of the instability wave season. During this time a distinctive 25-day periodicity is observed with amplitudes of up to $60 \mathrm{~cm} \mathrm{~s}^{-1}\left(30 \mathrm{~cm} \mathrm{~s}^{-1}\right)$ at $10 \mathrm{~m}(75$ m) depth.

The meridional temperature gradient $\left(T_{y}\right)$ at $10 \mathrm{~m}$ depth is relatively constant in magnitude and sign; however, during the instability wave season $T_{y}$ oscillates nearly in phase with the $v$-component. In contrast the $T_{y}$ oscillations at $75 \mathrm{~m}$ depth are approximately in quadrature with the $v$-component.

\section{Results}

\section{a. Temperature balance at $10 \mathrm{~m}$ depth}

The zonal, vertical, and meridional advective temperature fluxes; the negative value of their sum, $T_{t}^{*}$, and the observed local rate of change of temperature, $T_{t}$, are shown in Fig. 4. All of these time series are computed using four-day running means, and the corresponding Reynolds' fluxes are omitted since they are negligibly small (less than $10^{-7}{ }^{\circ} \mathrm{C} \mathrm{s}^{-1}$ ) for this averaging interval. Consider the evolution of each flux term separately.

A relatively steady surface flow advects warm water eastward from March through May. But, due to the weak $T_{x}$, the rate of heating by zonal advection is unimportant at this time. By mid-June, when the surface flow has reversed and the magnitude of $T_{x}$ is rapidly increasing, westward advection of cold water attains its largest magnitude coincident with the instability wave season. After $T_{x}$ weakens in November the effects of zonal advection are again negligible.

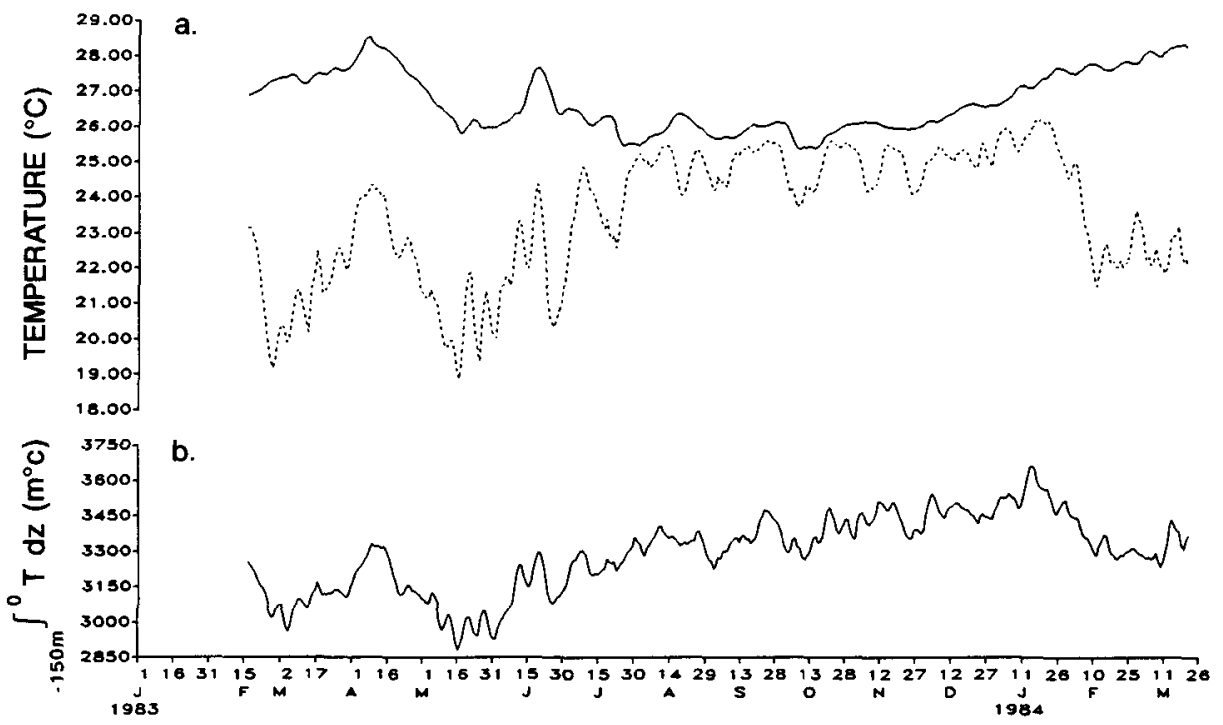

FIG. 2. Time series of (a) temperature at 10 (solid line) and $75 \mathrm{~m}$ (dotted line) depth and (b) upperocean heat $(0-150 \mathrm{~m})$ observed on the equator at $28^{\circ} \mathrm{W}$ smoothed with a 4-day running mean. 
a. VELOCITY COMPONENTS

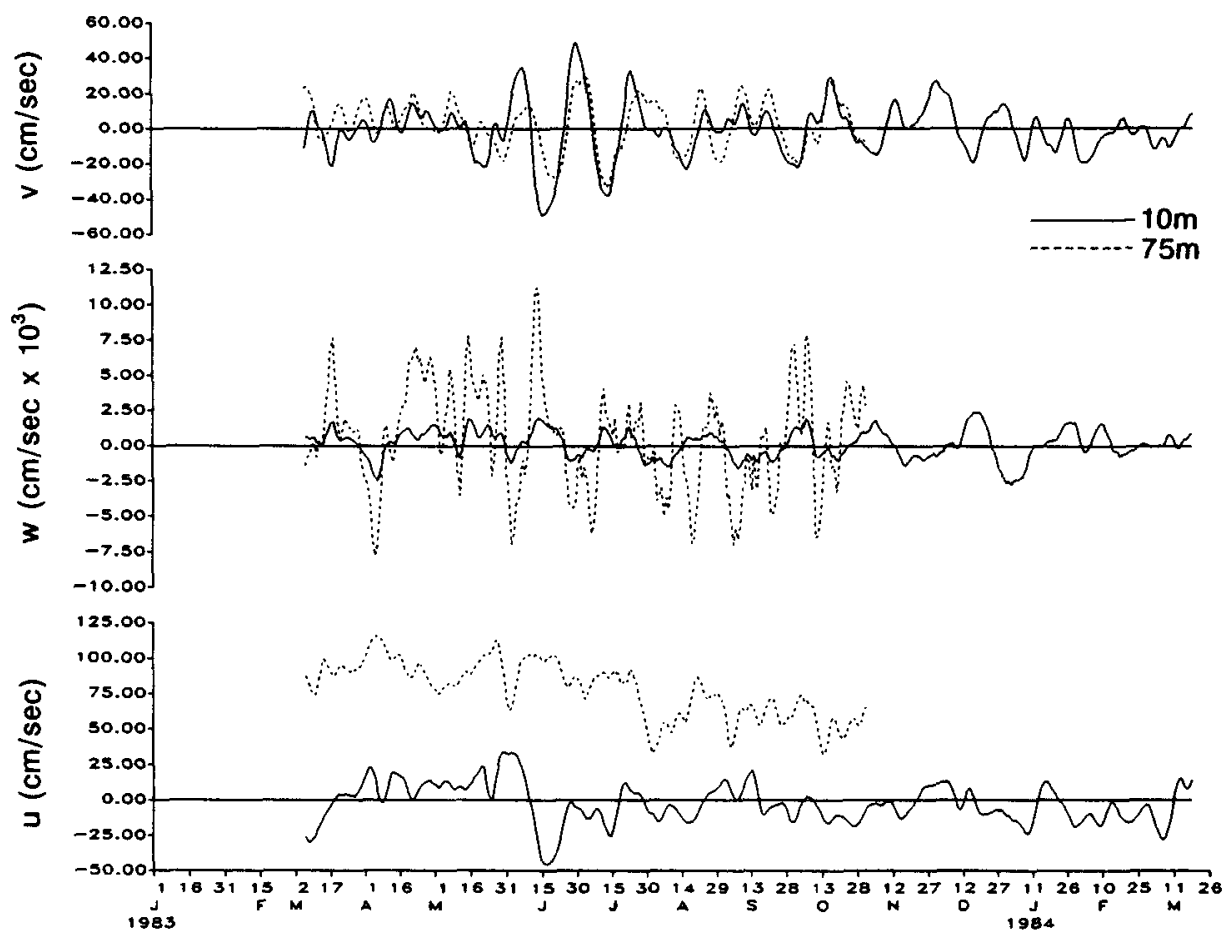

b. TEMPERATURE GRADIENTS

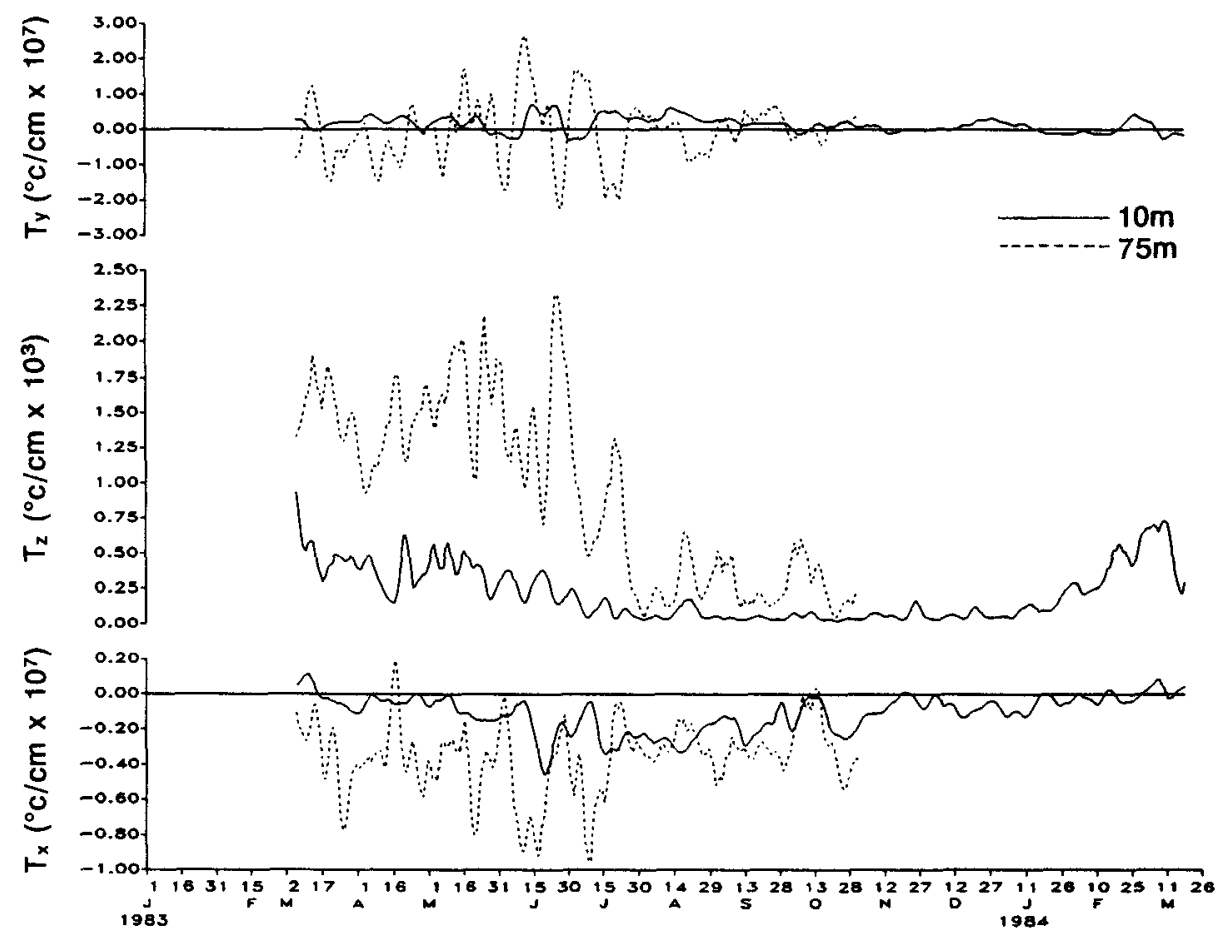

FiG. 3. From bottom to top: (a) time series of the zonal, vertical, and meridional components of velocity at $10 \mathrm{~m}$ (solid line) and $75 \mathrm{~m}$ (dotted line) depth and (b) time series of the zonal, vertical, and meridional components of the temperature gradient at $10 \mathrm{~m}$ (solid line) and $75 \mathrm{~m}$ (dotted line) depth. All time series were smoothed with a 4-day running mean. 


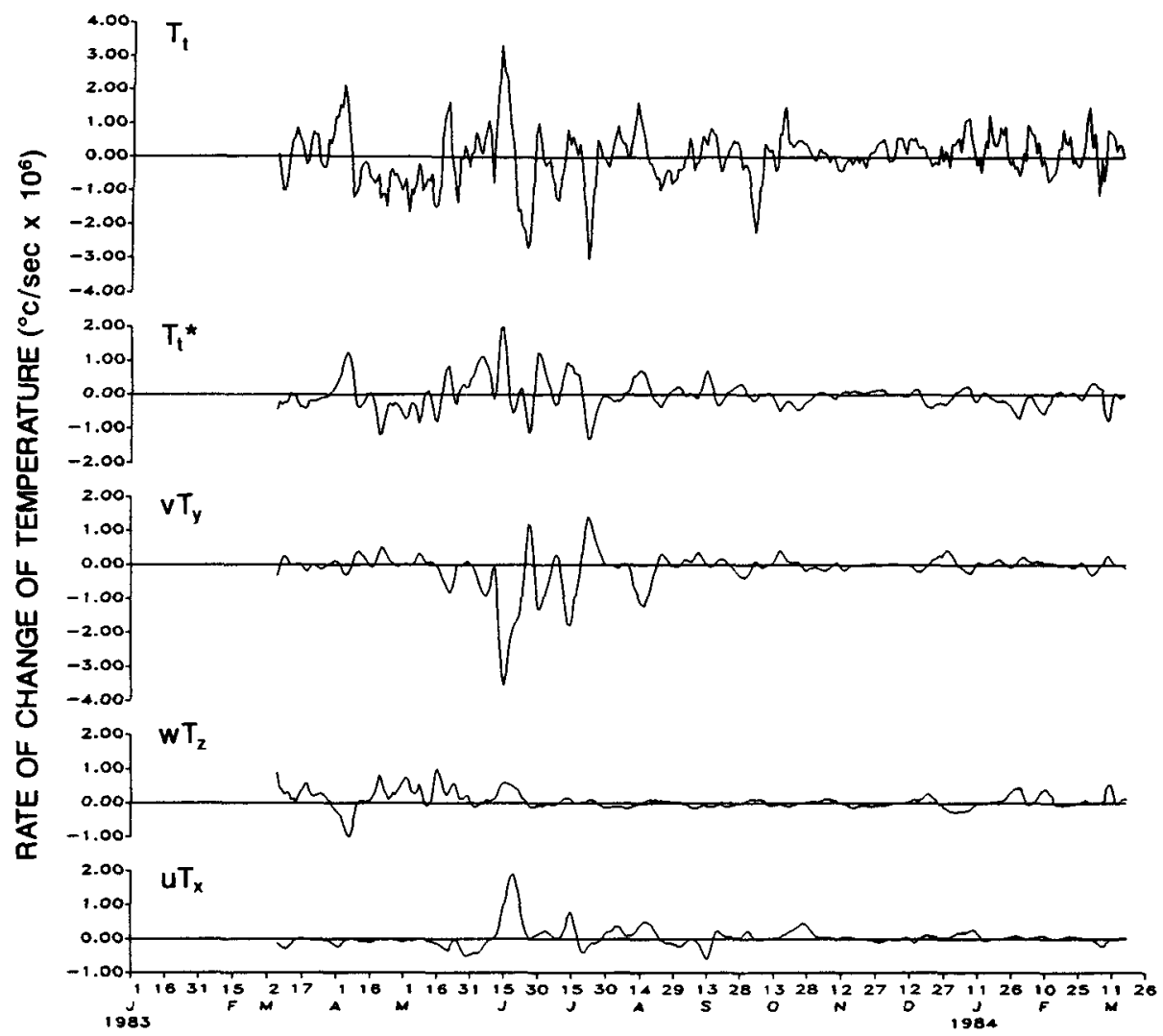

FIG. 4. A 4-day running mean diagnosis of the temperature balance at $10 \mathrm{~m}$ depth. From bottom to top: time series of the zonal, vertical, and meridional temperature advection terms, the estimated $T_{i}^{*}$, and the observed $T_{t}$.

Vertical advection also varies seasonally. The downwelling caused by the basinwide easterly wind stress relaxation event in March 1983 results in heating. The upwelling, accompanying the basin-wide easterly wind stress intensification, then results in cooling. Weingartner and Weisberg (1991) showed that the decrease in SST during this upwelling period from $28.5^{\circ} \mathrm{C}$ in early April to $25.5^{\circ} \mathrm{C}$ in mid-May is accounted for by the vertical displacement of the $25.5^{\circ} \mathrm{C}$ isotherm from its initial depth of $65 \mathrm{~m}$. Upwelling-induced cooling continues through the instability wave season after which the influence of vertical advection subsides due to the decrease in $T_{z}$. Cooling by vertical advection is again observed in January 1984 after the easterlies have relaxed and the thermocline begins to rise.

The meridional advection term has its largest influence during the instability wave season. Heating occurs as a consequence of rectification between the $v$-component and $T_{y}$.

The estimated $T_{t}^{*}$ time series thus evolves as the resultant of several different processes. Vertical advection due to the basinwide changes in easterly wind stress are controlling through the onset of the instability wave season. Thereupon horizontal advection (primarily meridional) takes hold. By September, after the ther- mocline has adjusted, the instability waves have abated and the temperature gradients have weakened, the advective fluxes all tend to be small and cancelling. Their effects are not observed again until the easterlies relax and the thermocline begins to adjust to a new state, whereupon vertical advection is again controlling.

Visual inspection shows a general agreement between the estimated $T_{t}^{*}$ and the observed $T_{t}$. The agreement is best from March through September 1983 when the advective fluxes are largest. The fluctuations also agree during the latter part of the record; however, from early December 1983 through March 1984 the observations indicate a warming trend while the advective terms show cooling, implying that something else must be governing the trend in SST at this time. Figure 5 shows the coherence squared $\left(\gamma^{2}\right)$, phase $(\phi$; in radians), and gain between $T_{t}^{*}$ and $T_{t}$, using daily mean data for the period 4 March-30 September 1983 when the advective fluxes are largest. Frequency domain averaging was performed over a $0.0016 \mathrm{cph}$ bandwidth for approximately 17 degrees of freedom. The $T_{t}^{*}$ and $T_{t}$ are coherent and in-phase at time scales longer than three days with the gain varying between 0.5 and 1.8 for time scales longer than five days. Only within the highly coherent instability wave band is the 


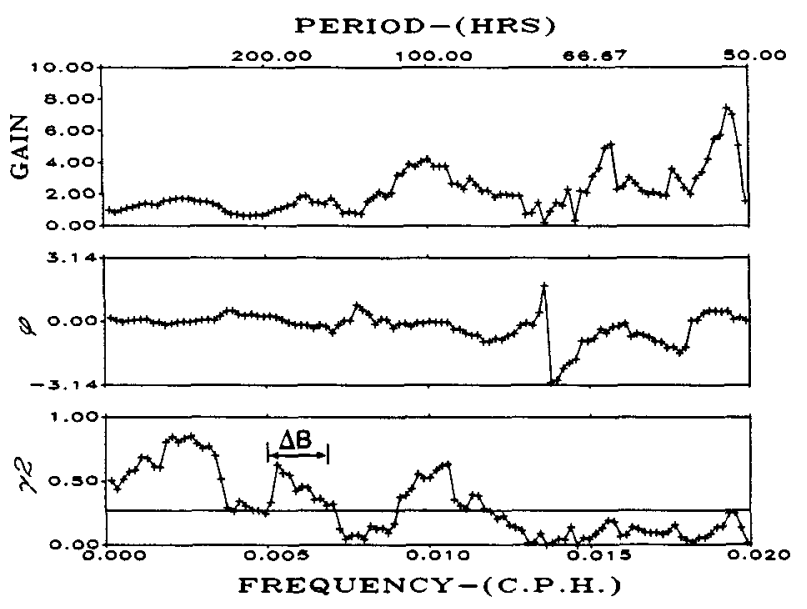

Fig. 5. Coherence squared, phase and gain between $T_{t}^{*}$ and $T_{t}$ at $10 \mathrm{~m}$ depth computed for the period from 4 March 1983 to 30 September 1983. Spectral averaging over a $0.0016 \mathrm{cph}$ bandwidth results in approximately 17 degrees of freedom and the corresponding $90 \%$ significance level for coherence squared is given by the horizontal line.

gain statistically different from 1.0 at the $90 \%$ confidence level, and there the advective fluxes slightly underestimate the observed variations in SST. These results show that the variations in SST are due primarily to advective fluxes when these fluxes are large. In section 5 it is suggested that the discrepancy in the steadily rising SST over the latter half of the record can be resolved by surface heat flux.

The lower frequency variations and the role of the Reynolds' fluxes during the instability wave season are addressed by recalculating the terms in Eq. (2) using 25 -day running means. The results are plotted in Fig. 6 . With respect to the 25-day running means, the cooling in SST following the increase in easterly wind stress is due primarily to upwelling and the subsequent heating is due to the instability wave-induced Reynolds' fluxes. These fluxes are prominent during the instability wave season with the meridional and the vertical components being convergent and the zonal component being divergent. Of principal importance to the seasonal evolution of SST is the large rate of heating from mid-May through mid-July due to $\left\langle v^{\prime} T^{\prime}\right\rangle_{y}$. Parameterizing this heat flux convergence in terms of a horizontal eddy diffusivity, $K_{h}=-\left\langle v^{\prime} T^{\prime}\right\rangle_{y} / T_{y y}$, results in $K_{h} \sim 2 \times 10^{8} \mathrm{~cm}^{2} \mathrm{~s}^{-1}$ during the wave season. When these waves are absent $K_{h}$ is at least an order of magnitude smaller. The zonal advection time series implies a cooling influence from June through October, but in contrast to $w T_{z}$ and $\left\langle v^{\prime} T^{\prime}\right\rangle_{y}$, this term shows little correspondence with the observed SST variability. Furthermore, from October through the end of the record there is no correspondence between the 25-day running mean $T_{t}^{*}$ and $T_{t}$ time series.

In summary, the roles of advective and Reynolds' heat flux convergences in the annual cycle of SST vary

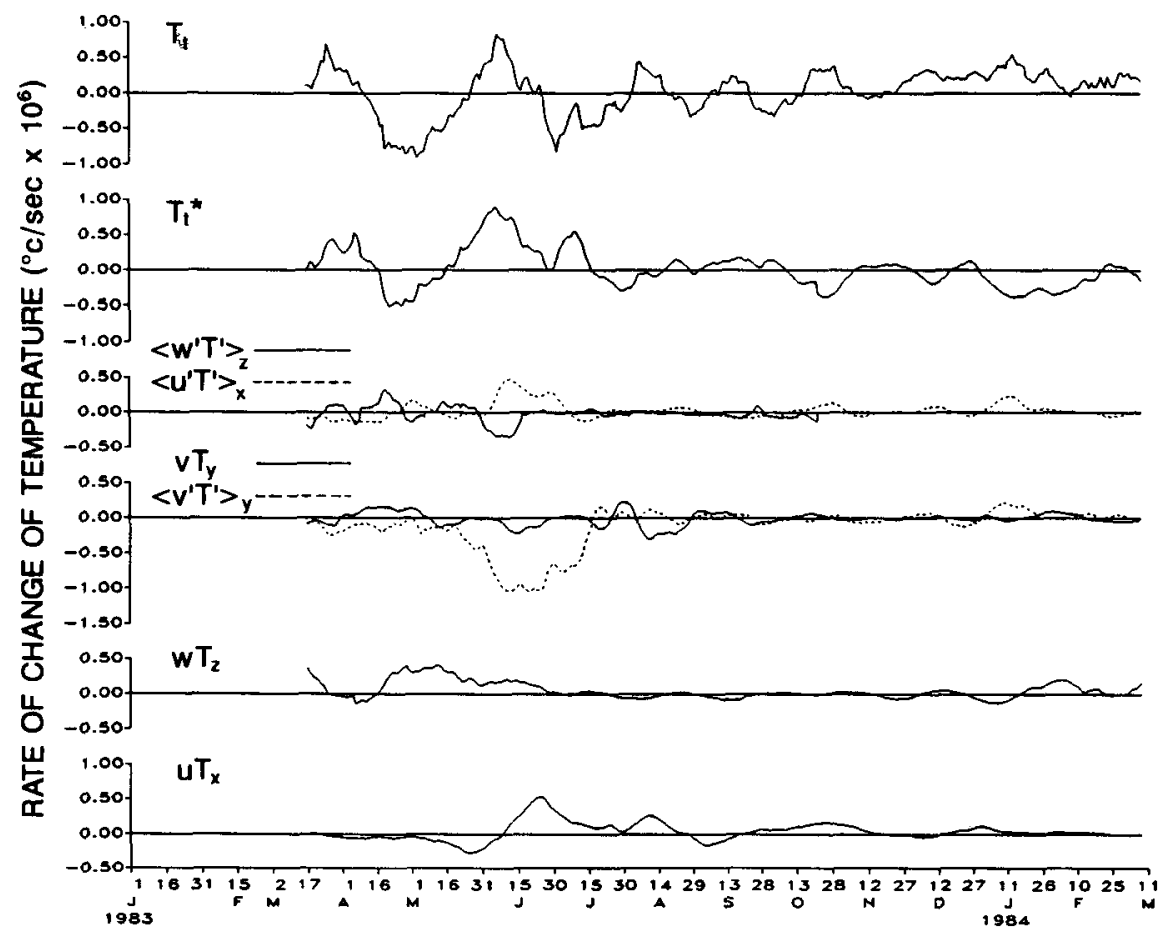

FIG. 6. A 25-day running mean diagnosis of the temperature balance at $10 \mathrm{~m}$ depth. From bottom to top: time series of the zonal, vertical, and meridional temperature advection terms, the Reynolds' heat flux convergences, the estimated $T_{t}^{*}$, and the observed $T_{t}$. 
seasonally. The observed decrease in SST following the boreal springtime intensification of easterly wind stress results primarily from vertical advection. This upwelling-induced cooling is halted and reversed with the onset of the instability wave season, due primarily to the meridional Reynolds' heat flux convergence associated with these waves. The zonal advection term is always of secondary importance and tends to counter first the upwelling-induced cooling and later the meridional Reynolds' heat flux-induced warming. All of these processes diminish in importance following the cessation of the wave season in late July because the nearly isothermal surface layer deepens, $T_{x}$ decreases in magnitude, the $u$-component is weak and variable, and the Reynolds' heat flux convergences are small. The subsequent evolution of SST through fall and winter is probably controlled by surface heat flux as will be discussed.

\section{b. Temperature balance at $75 \mathrm{~m}$ depth}

Similar diagnostic analyses were performed for the temperature variations at $75 \mathrm{~m}$ depth. Time series of the advective terms, the estimated $T_{t}^{*}$ and the observed $T_{t}$, computed from four-day running means are shown in Fig. 7. As is the case for SST, when computed using

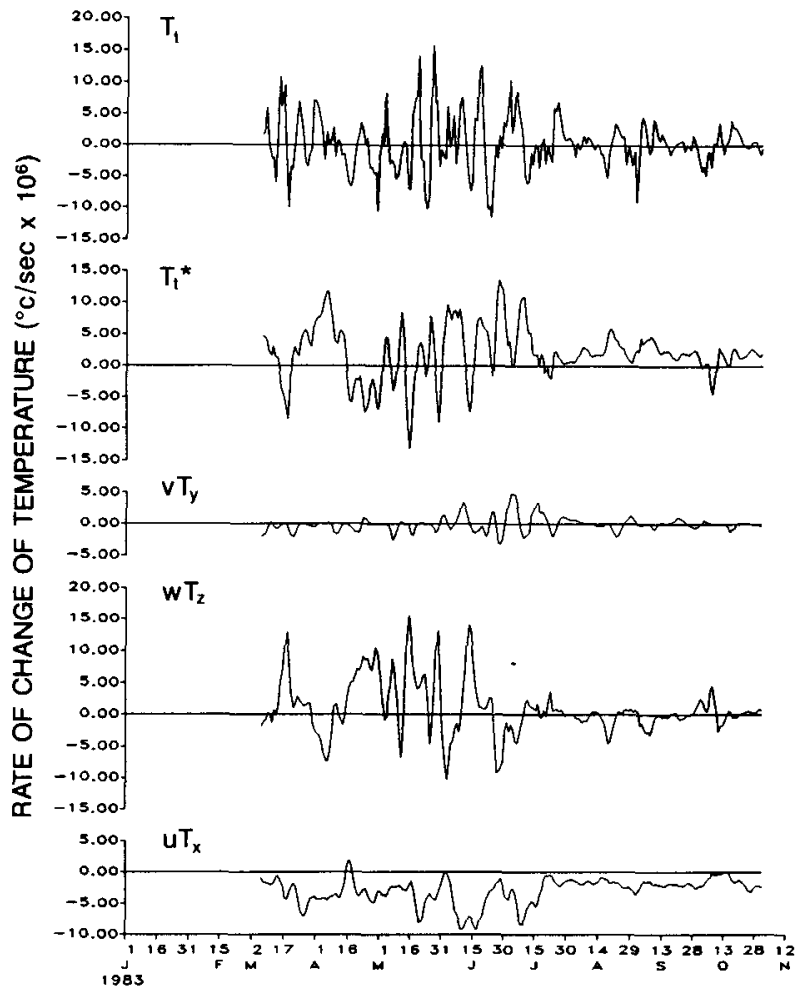

FIG. 7. A 4-day running mean diagnosis of the temperature balance at $75 \mathrm{~m}$ depth. From bottom to top: time series of the zonal, vertical, and meridional temperature advection terms, the estimated $T_{t}^{*}$, and the observed $T_{t}$. Note that the ordinate scale is five times larger than that in Fig. 4.

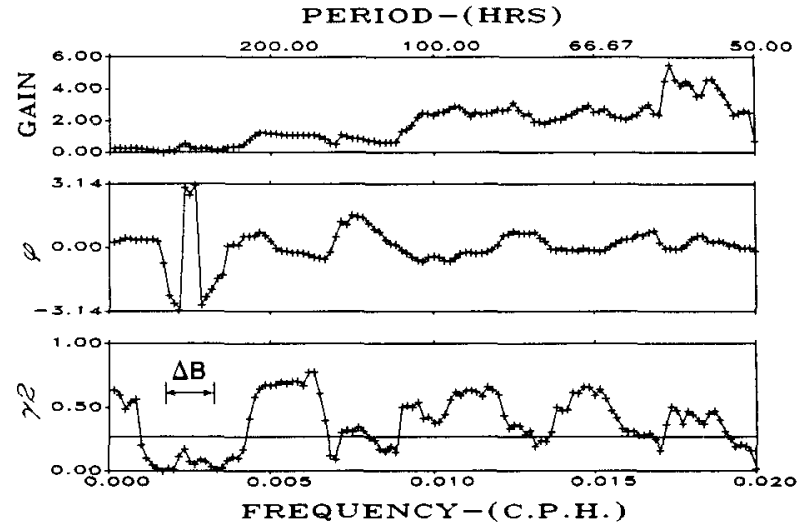

Fig. 8. Coherence squared, phase and gain between $T_{i}^{*}$ and $T_{t}$ at $75 \mathrm{~m}$ depth computed over the entire record: 4 March 1983-2 November 1983. Spectral averaging over a $0.0014 \mathrm{cph}$ bandwidth results in approximately 17 degrees of freedom and the corresponding $90 \%$ significance level for coherence squared is given by the horizontal line.

four-day running means, the component Reynolds' heat flux convergences are an order of magnitude smaller than the advective terms and are neglected.

The zonal component advects warm water eastward throughout the record, and at nearly constant rates from March through mid-May and from mid-July through early November. The difference in magnitude between the rates during these two periods is due primarily to the decrease in eastward speeds at $75 \mathrm{~m}$ depth as the EUC core deepens. The instability waves intervene during the transition resulting in large variability in $u T_{x}$ due to fluctuations in $T_{x}$.

The vertical component varies seasonally with the depth of the thermocline. Its magnitudes are largest from boreal spring through mid-summer when the thermocline is adjusting to the rapid variations in easterly wind stress. Downwelling-induced warming accompanies the March relaxation event, and upwellinginduced cooling occurs from mid-April through midMay as the easterlies intensify. Large variability then occurs during the instability wave season with $w T_{z}$ and $u T_{x}$ tending to vary out-of-phase. From August through September while the $w$-component is downward on average, $w T_{z}$ is small owing to small $T_{z}$.

Relative to either $w T_{z}$ or $u T_{x}$, and in contrast to the surface, the magnitude of $v T_{y}$ is small throughout the record. Thus, during the instability wave season, the advective influences upon the temperature variability within the thermocline are distinctly different from those at the surface.

As is the case with the surface, visual inspection of the estimated $T_{t}^{*}$ and the observed $T_{t}$ time series at 75 $m$ depth shows agreement in the phasing between the predominant high frequency fluctuations. Figure 8 shows the coherence analysis computed using daily means with frequency domain averaging over a 0.0014 
cph bandwidth for approximately 17 degrees of freedom. With the exception of the instability wave band the time series are generally coherent and in-phase. The coherence is greatest in the band corresponding to time scales of $6-10$ days where the gain is not statistically different from 1.0 . The gain is larger at higher frequencies which indicates that $T_{t}^{*}$ underestimates $T_{t}$ and conversely at lower frequencies.

The low frequency variations are addressed by recalculating the terms in Eq. (2) using 25-day running means as shown in Fig. 9. In contrast to the surface, the Reynolds' flux convergences at $75 \mathrm{~m}$ depth during the instability wave season are negligible. The only terms contributing to the low frequency variations in $T_{t}^{*}$ are thus $w T_{z}$ and $u T_{x}$. Comparison with $T_{t}$ shows agreement in phase while the thermocline is adjusting to the rapid easterly wind stress changes, although the magnitudes of the $T_{t}^{*}$ variations are two to four times larger than those for the observed $T_{t}$. These time series then deviate qualitatively from the middle of the instability wave season through the period after the thermocline has adjusted (i.e., from mid-June through the end of the record). Specifically from August through October, $T_{t}^{*}$ indicates a steady warming due to $u T_{x}$ whereas $T_{t}$ is on average zero during this time.

Can this advective heat imbalance be rectified by a diffusive heat loss? From August through October the middle of the thermocline defined by the $20^{\circ} \mathrm{C}$ isotherm lies at or below $100 \mathrm{~m}$ so a reasonable estimate of the second derivative of the temperature, $T_{z z}$, follows from the records at the 50,75 , and $100 \mathrm{~m}$ depths. The imbalance, estimated to be $-2.5 \times 10^{-6}{ }^{\circ} \mathrm{C} \mathrm{s}^{-1}$ from

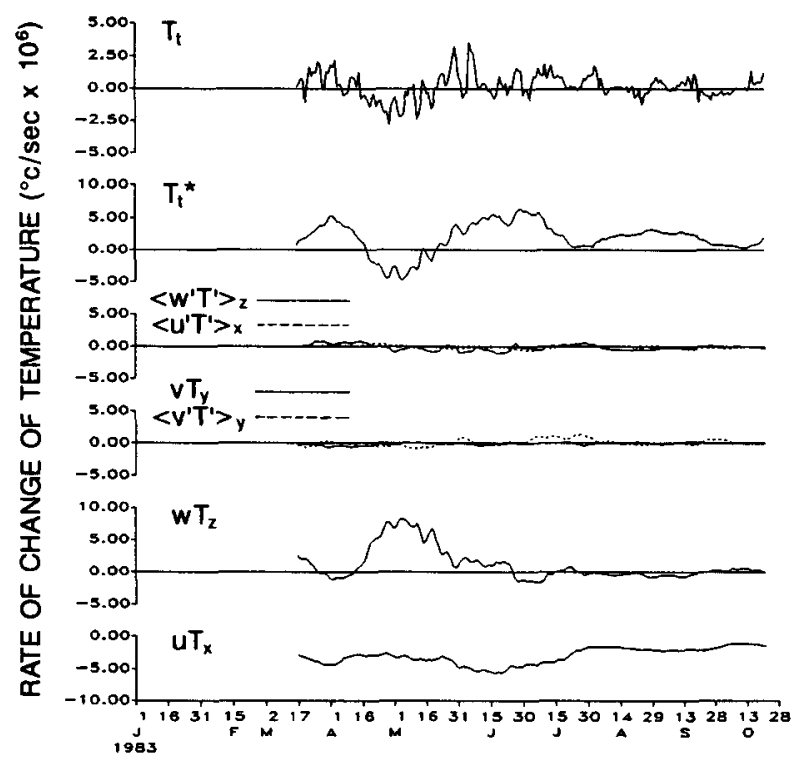

FIG. 9. A 25-day running mean diagnosis of the temperature balance at $75 \mathrm{~m}$ depth. From bottom to top: time series of the zonal, vertical, and meridional temperature advection terms, the Reynolds heat flux convergences, the estimated $T_{t}^{*}$, and the observed $T_{t}$. Note that the ordinate scale of $T_{t}^{*}$ is 4 times larger than that for $T_{t}$.

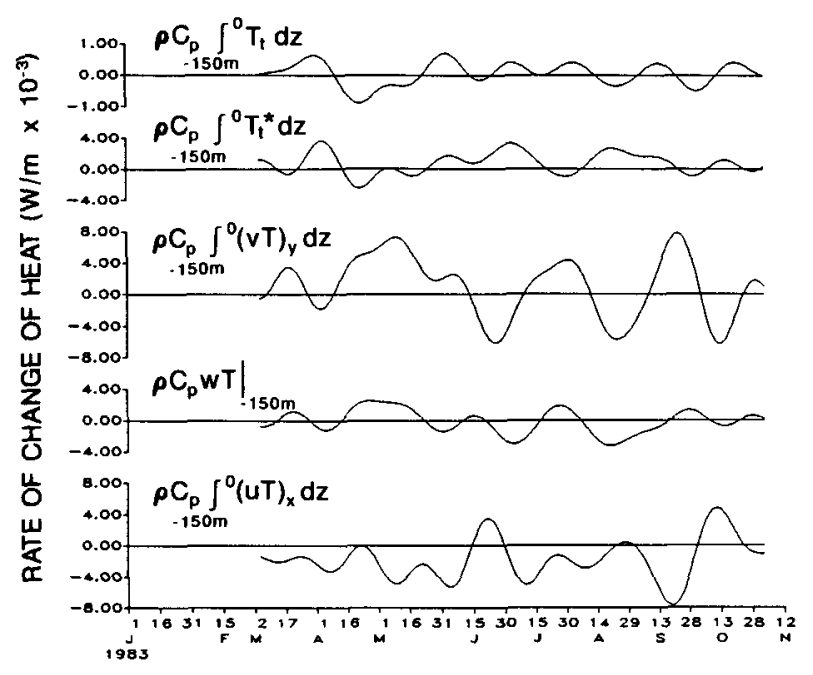

FIG. 10. A diagnosis of the vertically integrated heat balance. From bottom to top: time series of the upper $150 \mathrm{~m}$ vertically integrated zonal, vertical, and meridional heat flux convergence terms, the estimated $T_{t}^{*}$, and the observed $T_{t}$. Note that the ordinate scale of $T_{i}^{*}$ is four times larger than that for $T_{l}$. Positive (negative) values for the vertical heat flux convergence term indicate upwelling into (downwelling out of) the control volume defined between the surface and $150 \mathrm{~m}$ depth. Positive (negative) values for the horizontal terms imply a divergence (convergence) of heat out of (into) this control volume. All times series were low-pass filtered to remove fluctuations at periods shorter than 25 days.

Fig. 9, given $T_{z z}$ estimated to be $-6 \times 10^{-} 7^{\circ} \mathrm{C} \mathrm{cm}^{-2}$, requires a vertical eddy diffusion coefficient, $K$, of 4 $\times 10^{-4} \mathrm{~m}^{2} \mathrm{~s}^{-1}$. This estimate of $K$ is within the range reported by Moum et al. (1989) using microstructure measurements made at a similar position in the thermocline in the equatorial Pacific Ocean.

\section{c. Vertically integrated upper ocean heat balance}

The advective contributions to the heat balance, vertically integrated over the upper $150 \mathrm{~m}$ of the water column as described by Eq. (3), are shown in Fig. 10, low-pass filtered to exclude fluctuations at time scales shorter than 25 days. The zonal and meridional terms tend to vary out-of-phase with the zonal (meridional) term being convergent (divergent) on average and therefore resulting in warming (cooling). In contrast, the vertical component of the heat flux at $150 \mathrm{~m}$ depth follows the seasonal changes as described earlier with respect to the $w$-component. It is convergent from midApril through mid-May during the upwelling period and divergent from mid-May through mid-September during the downwelling period. Figure 11 shows the coherence analysis between the horizontal components of the vertically integrated heat flux convergence using daily mean values and a bandwidth of $0.0014 \mathrm{cph}$ for approximately 17 degrees of freedom. Coherence over a full bandwidth occurs only at time scales longer than 25 days (and hence the choice of filtering in Fig. 10). There the two components are out-of-phase with a gain 


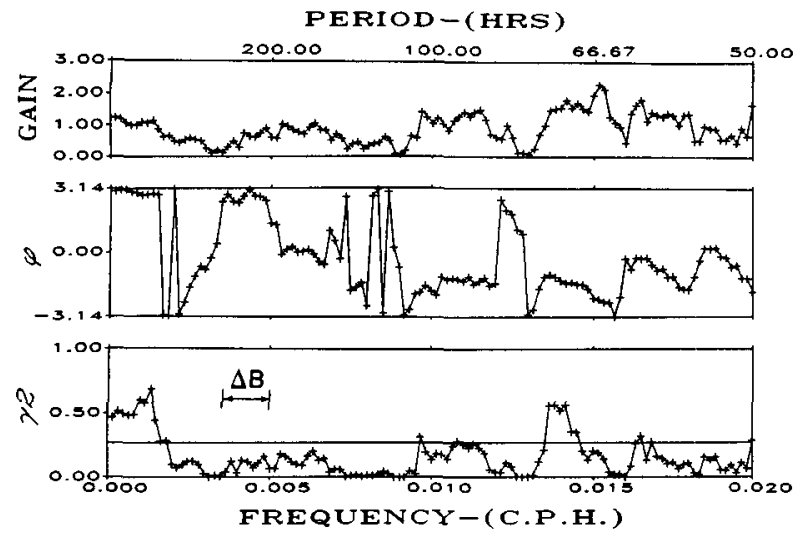

FIG. 11. Coherence squared, phase and gain between the vertically integrated $(u T)_{x}$ and $(v T)_{y}$ computed over the entire record: 4 March 1983-2 November 1983. Spectral averaging over a $0.0014 \mathrm{cph}$ bandwidth results in approximately 17 degrees of freedom and the corresponding 90 percent significance level for coherence squared is given by the horizontal line.

of about unity. This is consistent with equatorial longwave theory wherein a vertical advective flux arises as a small residual of approximately nondivergent horizontal fluxes. A coherence analysis between the vertically integrated $T_{t}^{*}$ and $T_{t}$ (not shown) yields a result very similar to that shown at $75 \mathrm{~m}$ depth. In this case the coherence at higher frequencies results from the vertical advective flux and the integrated meridional convergence. This finding implies that the higher frequency motions which contribute to the divergence on the equator are antisymmetric in the $v$-component. Consistency again exists with equatorial wave theory since odd mode inertia-gravity waves have a $u$-component minimum on the equator and therefore minimal zonal convergence of heat relative to meridional convergence.

Despite the qualitative agreement between the vertically integrated $T_{t}^{*}$ and $T_{t}$ the same quantitative dissimilarity exists as occurs at $75 \mathrm{~m}$ depth. There is either not enough downwelling or meridional divergence of heat to compensate for the zonal convergence of heat. For example, on average over the entire record, the vertically integrated $T_{t}^{*}$ is $610 \mathrm{~W} \mathrm{~m}^{-2}$, whereas the vertically integrated $T_{t}$ is $80 \mathrm{~W} \mathrm{~m}^{-2}$. Can this surplus heating rate be accounted for by vertical diffusion? Let the vertical diffusive heat flux at $150 \mathrm{~m}$ depth, $Q_{d}$, be given as

$$
Q_{d}=\rho C_{p} K T_{z} .
$$

Using the product $\rho C_{p}=4 \times 10^{6} \mathrm{~J} \mathrm{~m}^{-3}{ }^{\circ} \mathrm{C}^{-1}$ and $T_{z}$ $=0.08^{\circ} \mathrm{C} \mathrm{m}^{-1}$ (evaluated between 100 and $200 \mathrm{~m}$ depth), Eq. (5) implies that $K \sim 1.6 \times 10^{-3} \mathrm{~m}^{2} \mathrm{~s}^{-1}$. This $K$ is larger than that estimated at $75 \mathrm{~m}$ depth; however, the $150 \mathrm{~m}$ depth lies within the thermostad where Crawford and Osborn (1979) report values for $K$ of order $10^{-3} \mathrm{~m}^{2} \mathrm{~s}^{-1}$. While this surplus heating rate seems high, it is nearly an order of magnitude smaller than any of the advective terms from which it arises as a residual. As such, its error can not be quantified. However, it is interesting to note that the root-meansquared values for the vertically integrated $T_{t}^{*}$ and $T_{t}$ time series computed from daily means are approximately the same, indicating that the advective terms more closely account for the heat balance at higher frequencies where the advective time scales are shorter than the diffusive time scales.

\section{Discussion}

The underlying motive for upper-ocean heat balance studies is the understanding of the processes that control SST since this variable controls the heat exchange between the ocean and the atmosphere. The results of the foregoing section suggest that the annual cycle in SST on the equator at $28^{\circ} \mathrm{W}$ is accounted for by several independent processes occurring over different phases of the cycle. Advective processes are controlling when the ocean is adjusting to basin-wide changes in easterly wind stress. Commencing with the increase in easterly wind stress in boreal spring, the steady decrease in SST observed over a 4-6 week period is accounted for primarily by vertical advection. Following this period of upwelling-induced cooling, the surface currents become unstable, generating waves of approximately 25 -day periodicity. During this instability wave season, horizontal advection adds to the SST variability. These waves also result in a meridional convergence of Reynolds' heat flux. Zonal advection, rather than playing a major role in SST variability, serves only as a buffer to SST changes. Thus, during the upwelling-induced cooling period from early April through mid-May the surface flow advects warmer water eastward, and during the instability wave season the surface flow advects cooler water westward. By August all of these advective processes diminish in magnitude because 1) the nearly isothermal surface layer deepens, 2) the magnitude of $T_{x}$ decreases, 3 ) the $u$-component becomes weaker, and 4) the Reynolds' heat flux convergence abates.

From late summer through fall, after the advective effects subside and the thermocline is locally in equilibrium with the zonal wind stress, SST remains relatively constant and a nearly isothermal surface layer of about $70 \mathrm{~m}$ depth is observed (Fig. 2 and Weisberg et al. 1987). These observations and the small magnitudes of the advective terms suggest that surface heat flux and the vertical diffusion at the base of the mixed layer are balancing so that one-dimensional mixed layer models are applicable. If so, the isothermal layer depth should scale according to the Monin-Obhukov depth, $L$, which represents the depth over which the magnitudes of buoyancy and turbulent energy productions are similar (Phillips 1977), i.e., $L=u^{* 3} / \kappa B$, where $u^{*}=(|\tau| / \rho)^{1 / 2}$ is the wind friction velocity (assumed to be the dominant source of turbulent energy production $)$ and $\kappa(=0.42)$ is von Kármán's coefficient. 
The buoyancy production term, $B=\left(\alpha g / \rho C_{p}\right) Q_{a}$, where $Q_{a}$ is the net surface heat flux, $\alpha \quad(=3$ $\left.\times 10^{-4}{ }^{\circ} \mathrm{C}^{-1}\right)$ is the thermal expansion coefficient, and $g\left(=9.8 \mathrm{~m} \mathrm{~s}^{-2}\right)$ is gravity. For $Q_{a}=50 \mathrm{~W} \mathrm{~m}^{-2}$, according to the climatological estimates of Hastenrath and Lamb (1978), and $|\tau|=0.5$ dyn $\mathrm{cm}^{-2}$ (Colin and Garzoli 1987), $L \sim 65 \mathrm{~m}$, which is in agreement with the observations.

The steady rise in SST, which begins in early December, coincident with the seasonal relaxation in easterly wind stress, does not appear to be directly related to advection. Of the advection terms only $w T_{z}$ is of appreciable magnitude, but it acts to decrease SST by upwelling, as the thermocline adjusts basinwide to the change in wind stress, rather than increase it. We hypothesize that the observed rise in SST from December 1983 through March 1984 is therefore related to the surface heat flux being concentrated over a shallowing mixed layer. The thinning of the mixed layer is related to both the basinwide thermocline response (adiabatic ocean dynamics) as well as a reduction in turbulent energy production by local wind mixing. To examine this hypothesis let the difference between $T_{t}$ $\left(2.5 \times 10^{-7}{ }^{\circ} \mathrm{C} \mathrm{s}^{-1}\right)$ and $T_{t}^{*}\left(-1 \times 10^{-7}{ }^{\circ} \mathrm{C} \mathrm{s}^{-1}\right)$ be parameterized by the difference between the net heat flux at the surface and the vertical diffusion at the base of the mixed layer, $h$, taken at this time to be about $25 \mathrm{~m}$. Thus,

$$
T_{t}-T_{t}^{*}=\left(Q_{a}+Q_{d}\right)\left[\rho C_{p} h\right]^{-1}
$$

where $Q_{a}$ at this time is about $70 \mathrm{~W} \mathrm{~m}^{-2}$ (again from the climatology of Hastenrath and Lamb 1978). These values result in an estimated diffusive flux, $Q_{d}$, of -35 $\mathrm{W} \mathrm{m}{ }^{-2}$, which, using Eq. (5) and $T_{z}=0.08^{\circ} \mathrm{C} \mathrm{m}^{-1}$ (evaluated between 10 and $50 \mathrm{~m}$ depths), implies a vertical diffusion coefficient $K$ of $10^{-4} \mathrm{~m}^{2} \mathrm{~s}^{-1}$, again in agreement with the reported values of Moum et al. (1989). The hypothesis is thus consistent with these parameterizations.

The implications of these results are that $\left(Q_{a}+Q_{d}\right)$ varies seasonally and that their sum is 1 ) small in comparison to the advective heat fluxes after the boreal springtime intensification of easterly wind stress and during the instability wave season from March through June 1983, 2) approximately zero from August through November 1983 when advective heat fluxes are also small and SST is approximately constant, and 3) dominated by $Q_{a}$ from December 1983 through March 1984 when the advective fluxes are also small and the mixedlayer depth is decreasing due to both the shoaling of the thermocline in response to the seasonal and basinwide relaxation in easterly wind stress as well as the locally weak wind stress itself.

Is the foregoing diagnosis of the 1983/1984 SST annual cycle on the equator at $28^{\circ} \mathrm{W}$ representative of SST variability in other years and at other equatorial locations? The $28^{\circ} \mathrm{W}$ location was the only one where the terms in Eqs. (2) or (3) could be evaluated using
SEQUAL mooring data. However, additional wind and temperature data are available for extrapolating these results. At $28^{\circ} \mathrm{W}$ a similar annual cycle in temperature was observed over three consecutive years in conjunction with wind data from SPPR, suggesting that the results for the 1983/1984 annual cycle are representative of other years. At other locations there are similarities and dissimilarities in the seasonal evolution of SST. Figure 12 shows SST time series along the equator a $28^{\circ} \mathrm{W}, 24^{\circ} \mathrm{W}, 15^{\circ} \mathrm{W}$, and $4^{\circ} \mathrm{W}$ for the period February $1983-$ September 1984 . The overall character of the cycle is similar at each location with the magnitude of the variability increasing to the east. Not only does the Gulf of Guinea $\left(4^{\circ} \mathrm{W}\right)$ have the coldest SST in spring, it also has the warmest SST in winter. The easterlies intensify rapidly in the spring of both years beginning in early April 1983 and mid-May 1984. Coincident with these intensifications, SST decreases rapidly at each location with the duration of the decrease lasting longer, and hence SST becoming cooler, systematically to the east. The upwelling-induced cooling stops after 4-6 weeks, and at least at $28^{\circ} \mathrm{W}$ and $24^{\circ} \mathrm{W}$, warming is observed due to the meridional convergence of Reynolds' heat flux during the instability wave season. These waves are absent at $4^{\circ} \mathrm{W}$ (Weisberg and Weingartner 1988), but Houghton and Colin (1987) reported a similar equatorward Reynolds' heat flux con-

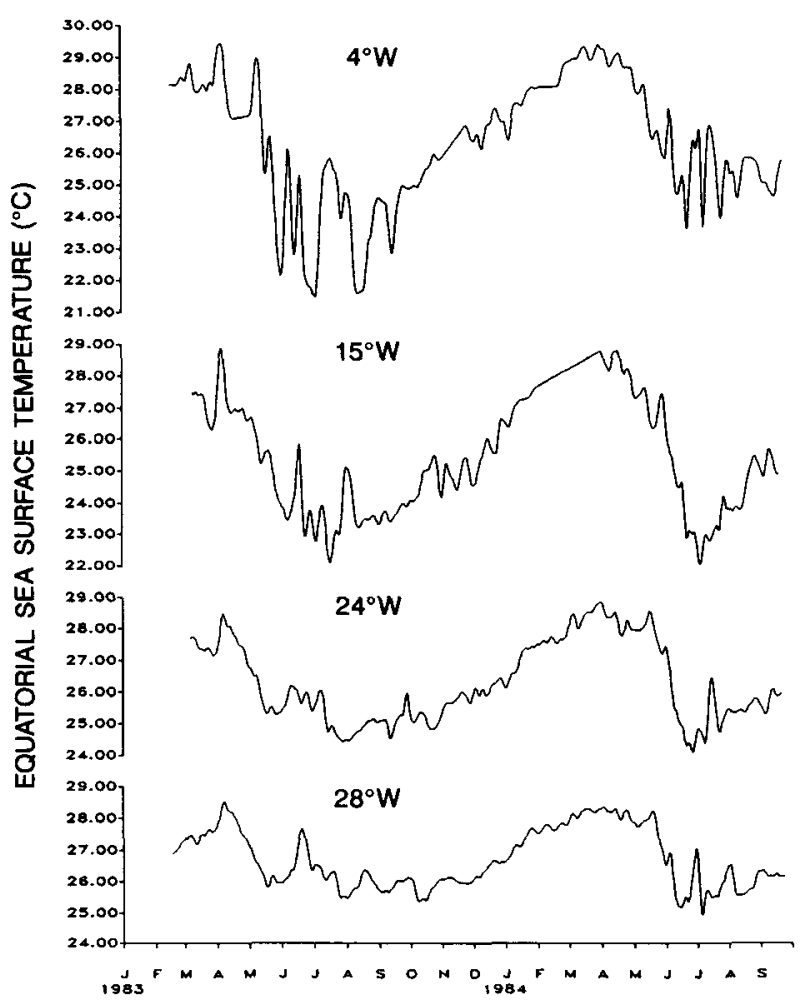

FIG. 12. Temperature time series at $10 \mathrm{~m}$ depth on the equator at (from bottom to top) $28^{\circ} \mathrm{W}, 24^{\circ} \mathrm{W}, 15^{\circ} \mathrm{W}$ and $4^{\circ} \mathrm{W}$, smoothed using a 4-day running mean. 
vergence due to local meridional wind stress component fluctuations from May through July. The character of the SST evolution among these locations then diverges from August through November. At $28^{\circ} \mathrm{W}$, SST remains relatively constant through the end of November. However, at the more eastward longitudes SST begins to rise at a rate that increases systematically to the east. Since advective processes should be similar or even cooling favorable at these longitudes, it is suggested that a combination of other factors control this eastward increase in the rate of SST rise. These include: 1) the systematic shoaling of the mixed layer, 2 ) the decrease in wind speed (and hence mixing), and 3 ) the increase in net surface heat influx (Hastenrath and Lamb 1978; Hastenrath and Merle 1987). Following the December easterly wind stress relaxation, SST rises at all longitudes and peaks by the end of March. A decrease in SST is observed at $15^{\circ} \mathrm{W}$ and $4^{\circ} \mathrm{W}$ between this time and mid-May 1984 when the easterly wind stress again intensifies. This SST decrease during the time of essentially no wind stress can be attributed to upwelling-induced cooling as the thermocline adjusts basinwide to the previous December's wind stress relaxation (Weisberg and Colin 1986; Weisberg and Tang 1987).

\section{Summary}

Temperature and velocity data, collected from a four-element array of surface moored current meters deployed during the SEQUAL Experiment, were used to investigate the role of ocean dynamics upon the seasonal evolution of SST, temperature at $75 \mathrm{~m}$ depth and upper-ocean heat on the equator at $28^{\circ} \mathrm{W}$. These data permitted evaluation of the advective and Reynolds' heat flux convergences which, upon summation, provided an estimate of the local rate of change of temperature (heat) for comparison with observations. The seasonal variations in SST may be explained by several different mechanisms; each operant at different phases of the annual cycle. Beginning with the boreal springtime intensification in easterly wind stress the observed rapid decrease in SST is attributed primarily to upwelling-induced cooling by vertical advection. Vertical advection thus causes the seasonal formation of the cold tongue along the equator in the central and eastern portions of the basin. Horizontal advection becomes important with the onset of the instability wave season wherein a meridional Reynolds' heat flux convergence results in increasing SST. Following the short-lived instability wave season, the advective and Reynolds' heat flux convergence terms all tend to be small and cancelling as reflected in relatively steady SST and mixed layer depth until the easterly wind stress relaxes in wintertime. SST then increases in response to the surface heat influx being concentrated over a shoaling mixed layer caused by a basinwide adjustment of the thermocline and a reduction in turbulent energy produc- tion. The cycle repeats anew with the next springtime intensification of easterly wind stress.

Ocean dynamics are therefore most important during the times when the thermocline is adjusting basinwide to the large scale changes in wind stress, either directly through large advective fluxes or indirectly by mediating mixed layer depth. Unexpectedly, the zonal advective temperature flux is not of primary importance; rather it serves to buffer the changes in SST due to upwelling and meridional Reynolds' heat flux convergence.

In.contrast to SST, Reynolds' heat flux convergence is unimportant in the temperature balance at $75 \mathrm{~m}$ depth wherein the primary advective contributions are zonal and vertical. This is not surprising since the instability waves which produce the Reynolds' heat flux are surface-confined. An imbalance between the estimated and observed local rates of temperature change may be accounted for by vertical diffusion. An estimate of the vertical eddy diffusivity required to redress this imbalance is $4 \times 10^{-4} \mathrm{~m}^{2} \mathrm{~s}^{-1}$. When analyzed as a control volume over the upper $150 \mathrm{~m}$ of the water column, all of the advective components are important in the heat balance and a similar order of magnitude estimate for the vertical eddy diffusivity is required.

While considerable uncertainty surrounds these results they are sufficiently encouraging to suggest that closure of the equatorial heat balance is feasible given long time series of upper-ocean horizontal velocity and temperature data with high vertical resolution collected from a closely spaced and multiple-scale moored array.

Acknowledgments. Support was provided by the Oceanography Section of the National Science Foundation under Grants OCE-8211848 for the data collection and OCE-8841927 for the data analyses. The authors thank T.-Y. Tang for many fruitful discussions and J. Donovan for assistance with data processing.

\section{APPENDIX}

\section{Computational Method and Error Analysis}

Equation ( 1 ) is derived by writing the temperature balance equation in terms of means and deviations (denoted by a prime) about these means:

$$
\begin{aligned}
& \left(T+T^{\prime}\right)_{t}=-\left[\left\{\left(u+u^{\prime}\right)\left(T+T^{\prime}\right)\right\}_{x}\right. \\
& \left.\quad+\left\{\left(v+v^{\prime}\right)\left(T+T^{\prime}\right)\right\}_{y}+\left\{\left(w+w^{\prime}\right)\left(T+T^{\prime}\right)\right\}_{z}\right] .
\end{aligned}
$$

Expanding and averaging Eq. (A1) over a specific time interval gives

$$
\begin{aligned}
T_{t}=-\left[(u T)_{x}+\left\langle u^{\prime} T^{\prime}\right\rangle_{x}+(v T)_{y}\right. \\
\left.+\left\langle v^{\prime} T^{\prime}\right\rangle_{y}+(w T)_{z}+\left\langle w^{\prime} T^{\prime}\right\rangle_{z}\right]
\end{aligned}
$$

In finite difference form the terms $(u T)_{x},(v T)_{y}$, and $(w T)_{z}$ are 


$$
\begin{aligned}
(u T)_{x}= & \left(u_{\mathrm{E}} T_{\mathrm{E}}-u_{\mathrm{W}} T_{\mathrm{W}}\right) / \delta x \\
= & \left(u_{\mathrm{E}}+u_{\mathrm{W}}\right)\left(T_{\mathrm{E}}-T_{\mathrm{W}}\right) / 2 \delta x \\
& \quad+\left(T_{\mathrm{E}}+T_{\mathrm{W}}\right)\left(u_{\mathrm{E}}-u_{\mathrm{W}}\right) / 2 \delta x \\
= & u T_{x}+T u_{x} \\
(v T)_{y}= & \left(v_{\mathrm{N}} T_{\mathrm{N}}-v_{\mathrm{S}} T_{\mathrm{S}}\right) / \delta y \\
= & \left(v_{\mathrm{N}}+v_{\mathrm{S}}\right)\left(T_{\mathrm{N}}-T_{\mathrm{S}}\right) / 2 \delta y \\
& \quad+\left(T_{\mathrm{N}}+T_{\mathrm{S}}\right)\left(v_{\mathrm{N}}-v_{\mathrm{S}}\right) / 2 \delta y \\
= & v T_{y}+T v_{y} \\
(w T)_{z}= & \left(w_{\mathrm{U}} T_{\mathrm{U}}-w_{\mathrm{L}} T_{\mathrm{L}}\right) / \delta \\
= & \left(w_{\mathrm{U}}+w_{\mathrm{L}}\right)\left(T_{\mathrm{U}}-T_{\mathrm{L}}\right) / 2 \delta z \\
\quad & \quad+\left(T_{\mathrm{U}}+T_{\mathrm{L}}\right)\left(w_{\mathrm{U}}-w_{\mathrm{L}}\right) / 2 \delta z \\
= & w T_{z}+T w_{z}
\end{aligned}
$$

where the subscripts $\mathrm{E}, \mathrm{W}, \mathrm{N}$, and $\mathrm{S}$ refer to the east, west, north, and south locations of the moorings from which the fluxes are estimated. The subscripts $U$ and $\mathrm{L}$ refer to the locations above (U) and below (L) the depth at which the vertical convergence of temperature is estimated. The terms $\left(T_{i}+T_{k}\right) / 2$ (where $i=\mathrm{E}, \mathrm{N}$, or $\mathrm{U}$ and $k=\mathrm{W}, \mathrm{S}$, or $\mathrm{L}$ ) are the average temperatures at the depth within the region specified by the moored array and approximated by the temperature observed on the equator at $28^{\circ} \mathrm{W}$ at the 10 and $75 \mathrm{~m}$ depths. Weingartner and Weisberg (1991) approximated the continuity equation as

$$
\begin{aligned}
& w_{z} \sim\left(w_{\mathrm{U}}-w_{\mathrm{L}}\right) / \delta z=-\left[\left(u_{\mathrm{E}}-u_{\mathrm{W}}\right) / \delta x\right. \\
&\left.+\left(v_{\mathrm{N}}-v_{\mathrm{S}}\right) / \delta y\right] \sim-\left(u_{x}+v_{y}\right) .
\end{aligned}
$$

Summing Eqs. (A3)-(A5), and using Eq. (A6) the terms $(u T)_{x},(v T)_{y}$, and $(w T)_{z}$ are

$$
\begin{aligned}
& (u T)_{x}+(v T)_{y}+(w T)_{z}=u T_{x}+v T_{y}+w T_{z} \\
& \sim\left(u_{\mathrm{E}}+u_{\mathrm{W}}\right)\left(T_{\mathrm{E}}-T_{\mathrm{W}}\right) / 2 \delta x+\left(v_{\mathrm{N}}+v_{\mathrm{S}}\right) \\
& \quad \times\left(T_{\mathrm{N}}-T_{\mathrm{S}}\right) / 2 \delta y+\left(w_{\mathrm{U}}+w_{\mathrm{L}}\right)\left(T_{\mathrm{U}}-T_{\mathrm{L}}\right) / 2 \delta z
\end{aligned}
$$

The term $\left(w_{\mathrm{U}}+w_{\mathrm{L}}\right) / 2$ is approximated by the $w$-component estimated by WW at 10 or $75 \mathrm{~m}$ depth. Thus, Eq. (A7) becomes

$$
\begin{aligned}
& u T_{x}+v T_{y}+w T_{z} \sim\left(u_{\mathrm{E}}+u_{\mathrm{W}}\right)\left(T_{\mathrm{E}}-T_{\mathrm{W}}\right) / 2 \delta x \\
& +\left(v_{\mathrm{N}}+v_{\mathrm{S}}\right)\left(T_{\mathrm{N}}-T_{\mathrm{S}}\right) / 2 \delta y+w_{h}\left(T_{\mathrm{U}}-T_{\mathrm{L}}\right) / \delta z
\end{aligned}
$$

The right-hand side of Eq. (A8) is the finite difference form used to estimate the first three terms on the righthand side of Eq. (2).

Time series of $T_{t}$ are estimated by multiplying the Fourier transform of the temperature time series by $-i \omega$, (where $i=\sqrt{-1}$ and $\omega$ is the frequency) followed by inverse Fourier transformation. All zonal (meridional ) derivative estimates are formed by forward (central) differences between the moorings on the equator at $24^{\circ} \mathrm{W}$ and $28^{\circ} \mathrm{W}$ (at $0.75^{\circ} \mathrm{N}$ and $0.75^{\circ} \mathrm{S}$ along $28^{\circ} \mathrm{W}$ ). The integrals in Eq. (3) were estimated by trapezoidal integration. Estimates of $T_{z}\left(\left\langle w^{\prime} T^{\prime}\right\rangle_{z}\right)$ at $10 \mathrm{~m}$ depth are calculated by forward differencing the temperatures $\left(\left\langle w^{\prime} T^{\prime}\right\rangle\right)$ between $10 \mathrm{~m}$ and $50 \mathrm{~m}$ depth. For most of the record when the $w$-component at 10 $\mathrm{m}$ depth is negative, $T_{z}$ is equal to $0.1^{\circ} \mathrm{C} / 10 \mathrm{~m}$. However, during the period of weak winds observed from 25 March through 9 April 1983 temperature sensors at the surface and at $10 \mathrm{~m}$ depth on the mooring at $0^{\circ} \mathrm{N}, 15^{\circ} \mathrm{W}$ show that $T_{z}$ in the upper $10 \mathrm{~m}$ is about $0.4^{\circ} \mathrm{C} / 10 \mathrm{~m}$, and this value of $T_{z}$ is used during this period. At $75 \mathrm{~m}$ depth $T_{z}\left(\left\langle w^{\prime} T^{\prime}\right\rangle_{z}\right)$ is calculated by forward differencing the temperatures $\left(\left\langle w^{\prime} T^{\prime}\right\rangle\right)$ at 50 and $75 \mathrm{~m}$ depth.

Three major sources of error may be identified: measurement error and the random and finite differencing errors due to sampling. If each horizontal velocity vector and temperature measurement consists of a signal plus an uncorrelated Gaussian deviation, the measurement error may be estimated directly from the finite difference versions of Eqs. (2) and (3) and the mean square values of the temperature, and the velocity components by calculating the rms deviation for each sample divided by the square root of the number of independent samples $\left(4 \mathrm{~h}^{-1}\right)$ obtained. For velocity sensor error, $\epsilon_{v}$, of $1 \mathrm{~cm} \mathrm{~s}^{-1}$ (Halpern 1987) and temperature sensor error, $\epsilon_{T}$, of $0.01^{\circ} \mathrm{C}$ the measurement errors are dominated by $\epsilon_{v}$. The estimated measurement errors for $v T_{y}$ and $u T_{x}$ are of order $10^{-7}{ }^{\circ} \mathrm{C}$ $\mathrm{s}^{-1}$ or less for periods greater than 1 day, and as discussed with respect to Figs. 4 and 7 these are negligible when the advective fluxes dominate the temperature balance equation. When applied to the vertical integrals of the horizontal heat flux convergences, the error analysis indicates that for periods longer than 25 (1) days the measurement error is about $16(80) \mathrm{W} \mathrm{m}^{-2}$, which is negligible compared to the estimates. As discussed by WW the measurement errors associated with the $w$-component (and hence the vertical advection terms ) are also small in comparison to the estimates over these time periods. Random sampling and finite difference errors are more difficult to quantify. However, the broad band coherence between $T_{t}^{*}$ and $T_{t}$ observed at periodicities between 2.5 and 10 days at $75 \mathrm{~m}$ depth (as well as the $0-150 \mathrm{~m}$ heat balance) suggests that these errors are not seriously impairing the estimates of the advective terms.

\section{REFERENCES}

Bjerknes, J., 1966: A possible response of the atmospheric Hadley circulation to equatorial anomalies of ocean temperature. Tellus, $18,820-829$.

- 1969: Atmospheric teleconnections from the equatorial Pacific. Mon. Wea. Rev., 97, 163-172. 
Cane, M., and E. S. Sarachik, 1977: Forced baroclinic ocean motions, II. The linear equatorial bounded case. J. Mar. Res., 35, 395432.

Colin, C., and S. L. Garzoli, 1987: In situ wind measurements and the ocean response in the equatorial Atlantic during the Programme Francais Ocean et Climat dans l'Atlantique Equatorial and the Seasonal Response of the Atlantic Ocean Experiment. J. Geophys. Res., 92, 3741-3750.

Crawford, W. R., and T. R. Osborn, 1979: Energetics of the Atlantic equatorial undercurrent. Deep-Sea Res., 26(Suppl), 309-324.

Enfield, D. B., 1986: Zonal and seasonal variations of the near-surface heat balance of the equatorial Pacific Ocean. J. Phys. Oceanogr., 16, 1038-1054.

Garzoli, S. L., and E. J. Katz, 1984: Winds at St. Peter and Paul rocks during the first SEQUAL year. Geophys. Res. Lett., 11, 715-718.

Haipern, D., 1987: Comparison of upper ocean VACM and VMCM observations in the equatorial Pacific. J. Atmos. Oceanic Technol., 4, 84-93.

Hastenrath, S., and P. J. Lamb, 1978: Heat Budget Atlas of the Tropical Atlantic and Eastern Pacific Oceans. University of Wisconsin Press, 104 pp.

- - and J. Merle, 1987: Annual cycle of subsurface thermal structure in the tropical Atlantic Ocean. J. Phys. Oceanogr., 17, 15181538 .

Houghton, R., and C. Colin, 1987: Wind-driven meridional eddy heat flux in the Gulf of Guinea. J. Geophys. Res., 92, 10777 10786.

Molinari, R. L., J. F. Festa and E. Marmolejo, 1985: Evolution of sea surface temperature in the tropical Atlantic Ocean during FGGE, 1979: II, Oceanographic fields and heat balance of the mixed layer. J. Mar. Res., 43, 67-81.

Moore, D. W., and S. G. H. Philander, 1977: Modeling of the tropical oceanic circulation. The Sea. E. Goldberg et al., Eds., WileyInterscience, 319-361.

Moum, J. N., D. R. Caldwell and C. A. Paulson, 1989: Mixing in the equatorial surface layer and thermocline. J. Geophys. Res., 94, 2005-2022.

Philander, S. G. H., and R. C. Pacanowski, 1986: The mass and heat budget in a model of the tropical Atlantic Ocean. $J$. Geophys. Res., 91, 14 212-14 220.

- J. Hurlin and R. C. Pacanowski, 1986: Properties of long equatorial waves in models of the seasonal cycle in the tropical Atlantic and Pacific Oceans. J. Geophys. Res., 91, 14 207-14 211.

Phillips, O. M., 1977: The Dynamics of the Upper Ocean. Cambridge University Press. $309 \mathrm{pp}$.

Richardson, P. L., and T. K. McKee, 1984: Average seasonal variations of the Atlantic equatorial currents from historical ship drifts. J. Phys. Oceanogr., 14, 1226-1238.

Sarmiento, J. L., 1986: On the north and tropical Atlantic heat balance. J. Geophys. Res., 91, 11 677-11 689.

Schopf, P., and D. E. Harrison, 1983: On equatorial waves and El Niño, I: Influences of initial states on wave-induced currents and warming. J. Phys. Oceanogr., 13, 936-948.

Seager, R. S., E. Zebiak and M. A. Cane, 1988: A model of the tropical Pacific sea surface temperature climatology. J. Geophys. Res., 93, 1265-1280.

Stevenson, J. W., and P. P. Niiler, 1983: Upper ocean heat budget during the Hawaii-to-Tahiti Shuttle Experiment. J. Phys. Oceanogr., 13, 1894-1907.

Weingartner, T. J., and R. H. Weisberg, 1991: On the annual cycle of equatorial upwelling in the central Atlantic Ocean. $J$. Phys. Oceanogr., 21, 68-82.

Weisberg, R. H., and C. Colin, 1986: Upper ocean temperature and current variations along the equator in the Atlantic Ocean during 1983-1984. Nature, 322, 240-243.

- , and T. Y. Tang, 1987: Further studies on the response of the equatorial thermocline in the Atlantic Ocean to the seasonally varying Trade Winds. J. Geophys. Res., 92, 3709-3727.

_- and T. J. Weingartner, 1988: Instability waves in the equatorial Atlantic Ocean. J. Phys. Oceanogr., 18, 1641-1657.

- , J. H. Hickman, T. Y. Tang and T. J. Weingartner, 1987: Velocity and temperature observations during the Seasonal Response of the Equatorial Atlantic Experiment at $0^{\circ}, 28^{\circ} \mathrm{W} . J$. Geophys. Res., 92, 5061-5075.

Wyrtki, K., 1981: An estimate of equatorial upwelling in the Pacific. J. Phys. Oceanogr., 11, 1205-1214. 